\title{
Genetic aspects of mitochondrial genome evolution
}

\author{
Matthias Bernt ${ }^{\mathrm{a}}$, Anke Braband ${ }^{\mathrm{b}}$, Bernd Schierwater ${ }^{\mathrm{c}, \mathrm{d}, \mathrm{e}}$, \\ Peter F. Stadler $\mathrm{f}, \mathrm{g}, \mathrm{h}, \mathrm{i}, \mathrm{j}, *$ \\ ${ }^{a}$ Parallel Computing and Complex Systems Group, Department of Computer Science, \\ University of Leipzig, Augustusplatz 10, D-04109 Leipzig, Germany \\ ${ }^{b}$ LGC Genomics GmbH, Ostendstr. 25, 12459 Berlin \\ ${ }^{c}$ ITZ, Ecology 83 Evolution, TiHo Hannover, Buenteweg 17d, 30559 Hannover, Germany \\ ${ }^{d}$ Department of Invertebrates, American Museum of Natural History, 79 St. at Central \\ Park West, New York, NY 10024, USA \\ ${ }^{e}$ Department of Molecular Cellular and Developmental Biology, Yale University, 165 \\ Prospect St., New Haven, CT 06511, USA \\ ${ }^{f}$ Bioinformatics Group, Department of Computer Science, and Interdisciplinary Center for \\ Bioinformatics, University of Leipzig, Härtelstraße 16-18, D-04107 Leipzig, Germany \\ ${ }^{g}$ Max-Planck-Institute for Mathematics in the Sciences, Inselstraße 22, D-04103 Leipzig, \\ Germany \\ ${ }^{h}$ Fraunhofer Institut für Zelltherapie und Immunologie - IZI Perlickstraße 1, D-04103 \\ Leipzig, Germany \\ ${ }^{i}$ Department of Theoretical Chemistry University of Vienna, Währingerstraße 17, A-1090 \\ Wien, Austria \\ ${ }^{j}$ Santa Fe Institute, 1399 Hyde Park Rd., Santa Fe, NM 87501, USA
}

\begin{abstract}
Many years of extensive studies of metazoan mitochondrial genomes have established differences in gene arrangements and genetic codes as valuable phylogenetic markers. Understanding the underlying mechanisms of replication, transcription and the role of the control regions which cause e.g. different gene orders is important to assess the phylogenetic signal of such events. This review summarises and discusses, for the Metazoa, the general aspects of mitochondrial transcription and replication with respect to control regions as well as several proposed models of gene rearrangements. As whole genome sequencing projects accumulate, more and more observations about mitochondrial gene transfer to the nucleus are reported. Thus occurrence and phylogenetic aspects concerning
\end{abstract}

*Bioinformatics Group, Department of Computer Science, University of Leipzig, Härtelstraße 16-18, D-04107 Leipzig, Germany

Email addresses: bernt@informatik.uni-leipzig.de (Matthias Bernt), phylogenetics@arcor.de (Anke Braband), bernd.schierwater@ecolevol.de (Bernd Schierwater), studla@bioinf.uni-leipzig.de (Peter F. Stadler) 
nuclear mitochondrial-like sequences (NUMTS) is another aspect of this review. Keywords: genetic code, gene content, chromosome structure, replication, transcriptome, phylogenomics

\section{Introduction}

Mitochondria are organelles with their own genetic material that are present in nearly all eukaryotic cells. In addition to the production of most of a cell's supply of ATP they are involved in many other key processes, such as the control of the cell cycle and cell growth (McBride et al., 2006). They share many features with prokaryotes and are commonly thought to have originated as endosymbionts in the ancestral eukaryote. A recent phylogenomic study suggests a common origin of mitochondria and the SAR11 clade of Alphaproteobacteria as a sister group to the Rickettsiales (Thrash et al., 2011).

Compared to the mitochondria found in other eukaryotic kingdoms, metazoan mitochondria are massively reduced in their genetic structure. A typical metazoan mitogenome consists of a single circular DNA that carries 13 intronless protein coding genes, the two subunits of the mitochondrial ribosomal RNA, and 22 tRNAs, one for each amino acid except leucine and serine, which have two copies each. Almost their complete proteome, much of which is of prokaryotic origin, is imported from the nucleus (Chacinska et al., 2009; Huynen, 2010). The expression of the few proteins encoded on the mitochondrial DNA (mtDNA) uses its own translation system and often employs lineage-specific variations of the genetic code. The mtDNA is not organised in nucleosomal bodies but instead associated with the mitochondrial inner membrane and several proteins including mitochondrial transcription factor A (mtTFA) and mitochondrial single-stranded DNA binding protein (mtSSB) (Bogenhagen et al., 2003). The inheritance of mtDNA is strictly maternal, with the single known exception of the doubly uniparental inheritance in unionid mussels (Breton et al., 2010).

In metazoan animals, the analysis of mitochondrial genomes with respect to size, genome architecture, gene content/arrangement, exon/intron structure, 
genetic code and secondary structure of rRNA and tRNA genes has been a powerful tool to infer phylogenetic relationships at different taxonomic levels (Boore, 2006). Furthermore, mitochondrial protein coding sequence data harbour valuable phylogenetic signal to further clarify uncertain relationships within and between phyla (Bourlat et al., 2008; Zardoya and Meyer, 1996).

This review is organized as follows: We first provide an overview of the general properties of mitochondrial genomes with a focus on the aberrant structures and the variations of the genetic code in metazoan metazoan phyla. In addition we address nuclear copies of mitochondrial DNA (NUMTS). Section 3 is concerned with opics related to replication of mitochondrial genomes, such as strand biases, a review of the models of replication itself, wmutation and repair, and mechanisms of genome rearrangements. Transcription of mitogenomes is treated in the last part of the paper.

\section{Genomics}

\subsection{Genome organisation}

A typical metazoan mitogenome encodes 13 proteins that belong to four enzyme complexes of the respiration chain: cytochrome b $(c o b)$, two subunits of ATP synthase (atp6,8), three subunits of cytochrome c oxidase (cox1-3), and seven subunits of NADH dehydrogenase (nad1-6, 4L), see Figure 1. The mitogenome furthermore contains the small and large $(r r n S, r r n L)$ RNA subunits of the mitochondrial ribosomes. These rRNAs are clearly of prokaryotic origin. A comprehensive review of gene content and genome organisation of animal mitochondria can be found in Gissi et al. (2008).

Typically, 22 tRNAs are encoded on the mtDNA. With the exception of serine and leucine, there is only a single tRNA for each amino acid. In many cases one or more mitochondrial tRNAs are missing and functionally replaced by nuclear tRNAs (Alfonzo and Söll, 2009). A peculiar feature are overlapping tRNAs, as in the case of $t R N A-\operatorname{Tr} p$ and $t R N A$-Cys in Arthropoda (Satta et al., 1987). Mitochondrial tRNAs, in contrast to tRNAs in other genetic systems, 
do not necessarily fold into the famous clover-leaf structure, although more than $90 \%$ of the known cases conform to the standard. Bizarre structures have evolved independently in many metazoan clades. The most frequent aberration

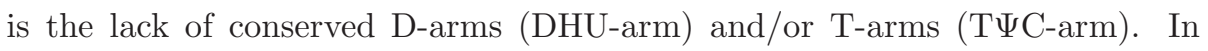
most Bilateria, $t R N A-S e r(A G N)$ lacks the D-arm. The corresponding deletion in $t R N A-\operatorname{Ser}(U C N)$ is prevalent among protostomes. In diverse taxa scattered throughout the Bilateria (e.g. Mammalia, Amphibia, and many Ecdysozoa) furthermore, one finds $t R N A s$-Cys without D-arm. A well known example for a systematic reduction of mt-tRNAs are Nematoda (Wolstenholme et al., 1994). With the exception of the two serine tRNAs, here the T-arm is deleted in all other tRNAs. Even the deletion of both the T- and the D-arm are not uncommon in particular in Enoplea (Jühling et al., 2012b). In Onychophora elaborate editing is capable of repairing large tRNA fragments (Segovia et al., 2011). Aberrant tRNAs structures have been collected and studied systematically as part of a recent effort to re-annotate mitochondrial tRNAs (Jühling et al., 2012a). Like their nuclear counterparts, mt-tRNAs are chemically modified. In some cases these are necessary to ensure correct folding (Helm, 2006). A 5-taurinomethyluridine found in Halocynthia roretzi at the anticodon wobble positions of $t R N A-M e t(A U R), t R N A-\operatorname{Tr} p(U G R)$, and $t R N A-G l y(A G R)$ appears to be responsible for the deciphering of the non-universal codes in ascidians.

Only a small fraction of most metazoan mitogenomes does not code for one of the proteins, rRNAs, or tRNAs. In contrast, the mitochondrial genomes of most other Eukarya are much larger and significantly differ in their gene content. While the gene content is extremely well conserved in animals, there are major differences among Metazoa in the arrangements of the few elements that regulate replication and transcription. In chordates, the most prominent noncoding region is the "displacement loop" (D-loop). It harbours almost all of the regulatory sequences for replication and transcription, see the inset in Figure 1. A second non-coding region of only $\sim 30$ nt located inside a tRNA cluster harbours the origin of replication for the L-strand in vertebrates (Fernández-Silva et al., 2003). Arthropods, and possibly also nematodes, have a single large AT- 
rich non-coding region which contains the replication origins for both strands (Zhang and Hewitt, 1997; Saito et al., 2005). In many of the major metazoan clades little or nothing is known about the mitochondrial control structures. Mollusca may serve as an example. In Pulmonata, several small non-coding regions with poor conservation have been reported (Yamazaki et al., 1997), while Cephalopoda have large "unassigned regions" that in part contain repetitive sequences (Boore, 2006). Gastropod mitogenomes, on the other hand have several usually small non-coding regions that are AT-rich and contain clover-leaf like structures. One or more of them have been suggested as replication origins (Grande et al., 2008; Breton et al., 2009).

\subsection{Aberrant genome structures}

Deviations from the typical organisation are relatively rare and appear to be restricted to individual clades. In most cases, there are missing or additional genes, most frequently a loss of tRNA genes. In diploblasts, the deletion of many or even most tRNAs is a common phenomenon (Haen et al., 2010; Wang and Lavrov, 2008). Among protostomes, in particular Rotifera (Suga et al., 2008) and Onychophora (Braband et al., 2010) are affected. Marsupials are well known to have lost mt-tRNA-Lys (Dörner et al., 2001). For a recent comprehensive overview of tRNA losses we refer to (Jühling et al., 2012a), see also (Gissi et al., 2008). The protein coding gene that is missing most often is atp8. It is absent e.g. in many Nematoda and some Mollusca (Boore, 1999). According to both published annotations, surveyed e.g. in (Gissi et al., 2008), and the re-annotation of the animal genomes with MITOS (Bernt et al., 2012b, in this special issue), atp8 is lost in scattered cases throughout all major metazoan clades. These data show that the loss in Nematoda is not as wide-spread as previously thought and highlight Platyhelminthes as another hot spot for the loss of atp8. Due to the short and rapidly evolving sequence of atp 8 it remains uncertain, however, which of these cases are failures to detect the gene and which are true gene losses. In octocoral mitogenomes an additional msh 1 gene is found (McFadden et al., 2006, and references therein). It has recently been 
identified as a compelling candidate for horizontal gene transfer and appears to have a function in DNA repair (Bilewitch and Degnan, 2011).

In some cases, however, the genome structures are dramatically different, see Table 1. The mitogenome of the human body louse Pediculus humanus, for instance has disintegrated into 18 mini chromosomes with a size of 3-4kb each containing 1 to 3 genes. Other sucking lice (but neither chewing lice nor Psocoptera) have a similar genome structure (Shao et al., 2009; Cameron et al., 2011). There is unequivocal evidence for recombination between different mini chromosomes, although the mechanism remains unknown (Shao and Barker, 2011). Multipartite mitogenomes have also been reported for the isopod Armadillidium vulgare (Raimond et al., 1999), the rotifer Brachionus plicatilis (Suga et al., 2008) and the nematode Globodera pallida (Armstrong et al., 2000). In the latter, the gene content between chromosomes is partially redundant and contains repetitive sequences that have been speculated to play a role in replication (Armstrong et al., 2000). Medusozoa (Cnidaria excluding Anthozoa) feature linear chromosomes that are split into two or more different molecules (Voigt et al., 2008; Kayal et al., 2012).

At least in mammals, different topological organizations of the mitogenomic DNA have been reported. Besides the usual, circular DNA also linear molecules and a variety of concatenated forms are present in varying amounts (see Pohjoismäki and Goffart, 2011, and references therein). Data for a comparative analysis of phenomenon within Metazoa seem to be absent.

Unionid mussels form an exception from the otherwise strict maternal inheritance of mitochondria. The doubly uniparental inheritance (DUI) found in all dioecious freshwater mussel species lead to highly differentiated mitogenomes between the two sexes (Breton et al., 2010; Doucet-Beaupré et al., 2010). The female form has an extra protein coding gene called the F-ORF, while the male form shows some rearrangements of the gene order and features a unique 3'coding extension of the cox2 subunit.

In the metazoan key phylum Placozoa (Schierwater, 2005) the mitochondrial genomes display several ancestral metazoan features (Dellaporta et al., 2006; 
Table 1: Examples of aberrant structures of metazoan mitogenomes.

\begin{tabular}{lll}
\hline Taxon & Description & Reference \\
\hline Phthiraptera & mini circles & Cameron et al. (2011) \\
Globodera & multiple chromosomes & Armstrong et al. (2000) \\
Armadillidium & linear + circular & Raimond et al. (1999) \\
Brachionus & 2 chromosomes & Suga et al. (2008) \\
Medusozoa & linear fragments & Kayal et al. (2012) \\
\hline Porifera & hairpin-forming repeats & Erpenbeck et al. (2009) \\
\hline Onychophora & tRNA loss & Podsiadlowski et al. (2008) \\
Chaetognatha &,,-- & Helfenbein et al. (2004) \\
Cnidaria &,,-- & Kayal and Lavrov (2008) \\
\hline Unionida & F ORFs & Breton et al. (2010) \\
Placozoa & several extra ORFs & Dellaporta et al. (2006) \\
& group I intron, split genes & Burger et al. (2009) \\
Porifera & group I intron & Rot et al. (2006) \\
Cnidaria & group I intron & Beagley et al. (1996) \\
Crassostrea & fragmented rRNAs & Milbury et al. (2010) \\
Annelida & group II intron & Vallès et al. (2008) \\
\hline
\end{tabular}

Signorovitch et al., 2007). The extended genome size of up to $43 \mathrm{~kb}$, the presence of introns, large intergenic regions and several ORFs of unknown function are shared characteristics with known metazoan outgroups like choanoflagellates such as Monosiga brevicollis (Burger et al., 2003) and therefore highlight a basal position of Placozoa at the root of the Metazoa. An unorthodox, fragmented cox1 gene is assembled by trans-splicing involving split group I introns and requires U-to-C editing (Burger et al., 2009). While such features are not uncommon in other eukaryotic kingdoms, they are highly exceptional among Metazoa.

In sponges (Phylum Porifera), large-scale mitochondrial genome sequencing has given important insights into phylogenetic relationships in Demospongiae (Wang and Lavrov, 2008) and Homoscleromorpha (Gazave et al., 2010) and highlighted the value of mitochondrial data for phylogenetic inferences. With a size of up to $29 \mathrm{~kb}$ (Lavrov, 2010) the largest sponge mitochondrial genome is smaller than the smallest placozoan mitogenome, displaying the general metazoan tendency for mitogenome size reduction due to lower proportions of non- 
coding regions. On the other hand, they feature unique non-coding repetitive sequences capable of forming hairpin structures (Erpenbeck et al., 2009).

In cnidarians the mitochondrial genome architecture is another and unique character to understand the evolution of mitogenomes within this phylum. Only the basal Anthozoa harbour circular mitochondrial genomes with a size of up to $21 \mathrm{~kb}$ (Medina et al., 2006), while the other cnidarian classes display linear chromosomes. In Hydrozoa and Cubozoa they are in addition fragmented into several pieces (Voigt et al., 2008; Kayal et al., 2012). The largest number so far, eight chromosomes, has been found in the the cubozoan Alatina moseri. Inverted repeat sequences form the telomeres in these genomes, which may have originated from transposons or plasmids (Nosek and Tomáška, 2003). In combination with the tendency to reduce the number of encoded tRNA genes the linear mitogenome architecture underlines the derived status of medusozoan mitogenomes (Ender and Schierwater, 2003). Several cnidarian mitogenomes harbour group I introns in their nad5 and cox1 genes (Beagley et al., 1996; Fukami et al., 2007).

Homing endonucleases have been reported in the group I introns found in Cnidaria as well as Porifera (Rot et al., 2006; Goddard et al., 2006). They are thought to play a role in the mobility and origin of these introns, which apparently arose by horizontal transfer from fungi (see e.g. Szitenberg et al., 2010). A single case of group II introns was reported for the cox1 gene in the mitogenomes of an annelid worm (Vallès et al., 2008).

The probably most derived mitogenomes within basal metazoan phyla are found in the Ctenophora. With a size of around $11 \mathrm{~kb}$ they are among the smallest animal mitogenomes. Like in cnidarians, ctenophoran mitogenomes have substantially reduced or even completely lost their mitochondrial encoded tRNA genes. The rRNAs as well as the protein coding sequences are highly derived in the Ctenophora, often leading to extremely long branches in phylogenetic analyses (Pett et al., 2011; Kohn et al., 2011).

Several instances of +1 frameshifts have been reported. For instance, a frameshift in the nad3 gene is conserved in the sauropsid mitogenomes (Mindell 
Table 2: Variations of the universal Genetic Code (UC) in Animal Mitochondria

\begin{tabular}{lccl}
\hline Codon & UC & Mod & Examples \\
\hline UGA & STOP & Trp & all Metazoa \\
\hline AUA & Ile & Met & Bilateria except Planaria \& Hemichordata \\
\hline AAA & Lys & Asn & Echinodermata, some Platyhelminthes \\
\hline AGA & Arg & Ser & most Bilateria \\
& & Gly & Tunicata \\
& & STOP & Vertebrata \\
\hline AGG & Arg & Ser & most Bilateria \\
& & Ser $/$ Lys & Arthropoda \\
& & Gly & Tunicata \\
& & STOP & Vertebrata \\
\hline UAA & STOP & Tyr & Planaria, Nematoda \\
\hline
\end{tabular}

et al., 1998; Russell and Beckenbach, 2008). Another well-described case is the cob gene in the ant genus Polyrhachis (Beckenbach et al., 2005) and in oysters (Milbury and Gaffney, 2005).

\subsection{Genetic Codes}

Several codons do not have their standard meaning in some or all animal mitochondria. Interestingly, the variations concern only codons for which the the first two positions do not determine the amino acid, and codons with a purine at the third position have been reassigned, see Table 2 .

The reassignment of codon appears to be intimately linked to the chemical modifications of the tRNAs (Santos et al., 2004). Indeed, most (and maybe all) tRNAs that decode the known non-universal codons in animal mitochondria are chemically modified, usually in their anticodon wobble position. Evolutionary scenarios that link the emergence of code variations and changes in tRNA modifications are reviewed in (Watanabe and Yokobori, 2011), see also (Abascal et al., 2012).

\subsection{NUMTs: nuclear copies of mitochondrial DNA}

The exchange of DNA between the nucleus and mitochondria (as well as chloroplasts) is a common phenomenon throughout the eukaryotes. Repair of 
double-stranded breaks by non homologous end-joining allows the inclusion of organellar DNA. Early in evolution this has led to the transfer of a large fraction of the mitogenomic information to the nuclear genome. The products of many of these genes are now re-imported while other genes of mitochondrial origin have acquired novel functions elsewhere (Kleine et al., 2009). Recent nuclear inserts of mitochondrial sequences, which occur at surprisingly high rate probably limited by the rates of double strand breaks (Hazkani-Covo et al., 2010), however, give rise to non coding and typically non-functional sequences. Nevertheless, a few NUMTs have been identified as the cause of genetic diseases (Chen et al., 2005). A recent example shows that they might also be a source of new spliceosomal introns (Curtis and Archibald, 2010). NUMTs can form a noticeable fraction of the nuclear genome: In the human genome at least 400kb (Hazkani-Covo and Graur, 2007), in Nasonia $\sim 43 \mathrm{~kb}$ and in Apis over 230kb of the nuclear DNA consists of NUMTs. In contrast, some genomes such as that of Drosophila melanogaster are nearly devoid of mitochondrial DNA (Viljakainen et al., 2010).

From a phylogenetic point of view, NUMTs are primarily an annoyance. In PCR-based approaches, unrecognised divergent NUMTs can introduce noise and unrecognised biases. In the DNA barcoding approaches, furthermore, they cause a systematic overestimate of the number of species (Song et al., 2008). Box 1 in (Hazkani-Covo et al., 2010) discusses in some detail artefactual results associated with unrecognised NUMTs. Nevertheless current genome annotations do not routinely provide NUMT data tracks. On the other hand, NUMTs have also been suggested as an interesting tool in primate phylogeny (Hazkani-Covo, 2009).

\section{Replication}

\subsection{Strand biases}

The two strands of mammalian mitochondrial genome have been found to differ in their nucleotide composition in an asymmetric manner. While one strand is rich in G the other is G poor. Since this difference is physically measurable 
(Anderson et al., 1981) the G rich strand is also termed heavy strand (H-strand) and the other light strand (L-strand). In particular one strand of mammalian mitogenomes has been reported to be GT rich (Reyes et al., 1998). In contrast (both strands) of the mitogenomes of Arthropoda are AT rich (Crease, 1999). But still the asymmetry favouring GT on one strand and AC on the other can be clearly observed in the 3rd codon position of protein coding sequences of most metazoan mitogenomes, in particular for fourfold degenerate sites. For several species, e.g. Branchiostoma (Cephalochordata), Florometra (Echinodermata), Katharina (Mollusc), and several Arthropod taxa (e.g. Tigriopus, Argiope, and Euscorpius), mitogenomes have opposite values (Hassanin et al., 2005; Wei et al., 2010).

The cause of the asymmetry is accounted to an asymmetric mutation process favouring transitions over transversions (Hassanin et al., 2005; Brown and Simpson, 1982). The likely source of this are hydrolytic deaminations of A and $\mathrm{C}$ (leading to $\mathrm{A} \rightarrow \mathrm{G}$ and $\mathrm{C} \rightarrow \mathrm{T}$ mutations) on the $\mathrm{H}$-strand which is prone to mutations when it is single stranded which happens during replication as well as during transcription, but to a lesser extent. This is consistent with the correlations found between the nucleotide frequencies as well as with the substitution rates and the time spent in a single stranded conformation during replication as measured by the distances to origin of the light strand $O_{L}$ (see Reyes et al., 1998; Krishnan et al., 2004). For some species a reversed bias in the nucleotide composition is observed, which might be caused by an inversion of the control region (Hassanin et al., 2005; Kilpert and Podsiadlowski, 2006; Wei et al., 2010).

Since nucleotide composition is related to amino acid composition (Min and Hickey, 2007) it has to be regarded in comparative analyses of amino acid sequences (Bernt et al., 2012a, in this special issue).

\subsection{Model(s) of replication}

The mtDNA is synthesised solely by DNA polymerase $\gamma$ (Bolden et al., 1977). So far, three additional accessory factors are known to be involved in mtDNA synthesis. A single-stranded DNA-binding protein (mtSSB) has been 
reported (Tiranti et al., 1993), which is thought to bind to the single stranded parental H-strand to protect it. Furthermore mtDNA helicase activity has been reported for both vertebrates (bovine brain) (Hehman and Hauswirth, 1992) and invertebrates (sea urchin) (Roberti et al., 1996), and topoisomerases responsible for relaxing (type I) and introducing (type II) supercoils are involved in mtDNA replication (Kosovsky and Soslau, 1993; Castora and Simpson, 1979).

The most widely accepted "orthodox" hypothesis explaining the mode of mtDNA replication is the so called strand displacement model (Robberson et al., 1972; Goddard and Wolstenholme, 1980; Clayton, 1982). We can give here only a brief outline and refer to the reviews by Shadel and Clayton (1997) and Taanman (1999) for much more detailed description of the replication process.

Primers for mtDNA H-strand replication are generated by the same process starting light strand transcription at the light strand promoter (LSP) (Chang et al., 1985) (see further Section 4). Whether light strand transcription is initiated or an RNA-DNA hybrid, called R-loop, is formed, is determined within the region of the heavy strand origin $\left(O_{H}\right)$, i.e. the part of the D-Loop region that harbours three conserved sequence blocks (CSB) (Walberg and Clayton, 1981). The RNA in the R-loop is further processed by RNase MRP which yields the primers for mtDNA H-strand replication. The H-strand synthesis is then started by the elongation of the RNA primer by DNA Polymerase $\gamma$. Most DNA H-strand replication processes are terminated immediately after initiation at a location harbouring one or more short $(\approx 15 \mathrm{nt})$ termination associated sequences (TAS) and produce a stable triple stranded DNA-DNA hybrid called the D-loop structure. Alternatively, the H-strand replication proceeds unidirectionally from the short stretch of displaced mtDNA across the the D-loop until it reaches the light-strand origin $O_{L}$. At this short $(\approx 30 \mathrm{nt})$ non-coding region (which in Mammalia is located within a cluster of tRNAs), the displacement of the $\mathrm{H}$-strand is thought to trigger the formation of a stem-loop structure (Martens and Clayton, 1979). This structure seems to be involved in the recognition by a DNA primase (Wong and Clayton, 1986) initiating L-strand replication. Since the stem loop structure is not universally present also the 
structural elements of the surrounding tRNAs might be involved in this process (Shadel and Clayton, 1997). L-strand replication then proceeds in the direction opposite of the direction of $\mathrm{H}$-strand replication. The replication of both strands continues until the replication of the $\mathrm{H}$-strand terminates and the two molecules are segregated. The remaining, so far unsynthesised part between $O_{H}$ and $O_{L}$ of the L-strand is finished after the segregation. Due to the delayed start of the L-strand replication the parental H-strand becomes single stranded with the advancing $\mathrm{H}$-strand replication until the L-strand replication renders it double stranded again. The time which a position on the $\mathrm{H}$-strand is single stranded depends on the distance to the origins as well as the speed of L- and $\mathrm{H}$ strand replication. While in the mitogenomes of Mammalia the $O_{L}$ is reported approximately $2 / 3$ of the genome length after the $O_{H}$, this is even more extreme in insects, where it is located $97 \%$ after the $O_{H}$ (see Saito et al., 2005). Replication of insect mtDNA is extremely asymmetric. Since the structure of the control region in mammals/chordates (Sbisá et al., 1997; Saccone et al., 1991) and insects (Saito et al., 2005; Zhang and Hewitt, 1997) is very different it is unclear at present whether the same mechanisms are responsible for initiation and termination of replication throughout the Metazoa.

As an alternative to the strand displacement model, a coupled mode of leading and lagging strand replication, called strand-coupled model, is discussed in the literature (Holt et al., 2000; Yang et al., 2002). Contrary to the orthodox model it is assumed that a replication bubble originates preferentially from an interval located near $O_{H}$ spanning approximately one quarter of the mitogenome (Bowmaker et al., 2003; Reyes et al., 2005).

In this model stretches of RNA/ribonucleotides are unevenly incorporated mainly in the daughter L-strand (see also Pohjoismäki et al., 2011). It has been argued that different analysis methods may degrade these stretches resulting in replication intermediates with single stranded DNA that gave rise to the strand displacement model. Most recently, the possibility of bidirectional replication and multiple replication origins scattered throughout the mitogenome have been discussed for the strand-coupled model of replication (Bowmaker et al., 2003; 
Reyes et al., 2005). It is still unsolved whether there are two different replication mechanisms generating the different kinds of observed replication intermediates, if the replication mechanisms are employed in a tissue specific manner, or if one of the two models is wrong. For critical discussions of these issues see e.g. Clayton (2003); Fish et al. (2004); Brown et al. (2005); Pohjoismäki and Goffart (2011).

Not much is known about the replication of the mitogenomes with a noncircular chromosome organisation, see Section 2.2. In the case of Globodera it has been suggested that repetitive sequences present on each of the mini circles play a role in replication (Armstrong et al., 2000). In analogy to fungal mtDNA, individual circular chromosomes might replicate independently (Armstrong et al., 2000). The replication mechanism of the linear mitogenomes of Cnidarians remains unknown at present. Putative genomic regions involved in replication have been identified for Hydra, although several plausible mechanisms known for other genetic systems have been ruled out for this species (Voigt et al., 2008), see also (Kayal et al., 2012). It seems to be promising to evaluate alternative mechanisms for mitogenome replication known for nonmetazoans with linear or multipartite mitogenomes (see e.g. Bendich, 2010, for some recent progress).

\subsection{Mutation and Repair}

With a few exceptions such as Octocoralia (McFadden et al., 2006), metazoan mitogenomes are subject to strong mutational pressures (Brown et al., 1979) that are associated with an inaccurate DNA repair system compared to nuclear DNA (Bogenhagen, 1999; Gredilla, 2011), the lack of protective chromosome-associated proteins, and the replication mechanisms outlined above that expose single-stranded intermediates. In addition, mitochondrial DNA is subject to high levels of oxidative damage (Harman, 1972). In conjunction with relatively small population sizes and the virtual absence of recombination one would predict that mtDNA is subject to Muller's Ratchet (Muller, 1964), i.e. a gradual accumulation of deleterious mutations and eventually complete loss 
of function. The strength of this effect depends on population size. Indeed, an increased number of amino acid substitutions has been reported from large mammals, which tend to have small populations (Popadin et al., 2007). Overall, however, the function of mitochondrial proteins is preserved by very strong selection, reviewed in detail in (Castellana et al., 2011).

Positive selection has been reported in particular for vertebrates and to an even larger extent for insect mitogenomes (Bazin et al., 2006). These findings have cast doubt on the usefulness of mtDNA as a means for estimating effective population sizes (see e.g. Meiklejohn et al., 2007).

\subsection{Genome rearrangements}

The arrangement of genes on the mitogenome shows a very high degree of variation across the Metazoa. A comparison of closely related species with different gene orders suggests that there are several types of "elementary" rearrangement events, see Figure 3: inversions (e.g. Asakawa et al., 1995), transpositions (e.g. Macey et al., 1997), inverse transpositions (e.g. Boore et al., 1998) (i.e. a transposition in which the re-inserted fragment is inverted), and tandem duplications followed by the random loss of one of the copied genes (Boore, 2000) (TDRL). Variants of the latter (Mueller and Boore, 2005) as well as tandem duplications in which the subsequent loss is not randomly distributed among the copies (Lavrov et al., 2002) have been discussed. Additionally changes in the gene content, i.e. deletions (Lavrov and Brown, 2001) or duplications (Zhong et al., 2008) and changes in chromosome organisation (see Section 2.2) have been reported for metazoan mitogenomes. Rearrangements can reveal unexpected high-level clades such as the subdivision of placozoan lineages in two different groups that probably represent higher taxonomic units (Eitel and Schierwater, 2010).

It is not entirely clear at present whether the rearrangement types deduced from a comparative analysis of mitogenomes correspond to distinct specific molecular mechanisms. For instance transpositions and non-tandem duplication random loss events can be interpreted as special cases of the TDRL model. 
It is also unresolved whether inverse transpositions are truly elementary operations or the composite of two subsequent steps. Conversely, several different molecular mechanisms might be at work to produce the same observable rearrangement event.

A variety of possible mechanisms causing duplications have been discussed in the literature (Boore, 2000), several of which are related to the replication process, such as slipped strand mispairing during replication (Broughton and Dowling, 1997), imprecise termination (Mueller and Boore, 2005) (where too early termination results in a deletion and too late in a duplication event), and other enzymatic errors causing e.g. erroneous identification of the origin of light-strand replication (Macey et al., 1997). In a study of recent duplications in geckos, slipped-strand mispairing was favoured (Fujita et al., 2007). Another potential route to TDRLs is the head-to-head or head-to-tail dimerisation of linearised monomeric mitogenomes (Lavrov et al., 2002). The head-to-head configuration would result in an inverted duplicate. Note that any mechanism that can result in a whole genome duplication, e.g. imprecise termination, might also account for head-to-tail dimerisation.

Illegitimate recombination may also cause changes in gene order. It provides a plausible explanation in particular for non-tandem duplicated segments (Mueller and Boore, 2005). Certain features of the mitogenomic sequence, such as small direct repeats (Macey et al., 1997), have been proposed to evoke rearrangements. Duplications might occur due to the formation of stem loop structures which are involved in replication (e.g. at the $O_{L}$ ), or during the maturation of transcripts, see Section 4.

As an alternative to (tandem) duplication (non)-random loss, transpositions could also be caused by a separate mechanism akin to the propagation of transposable elements (Calos and Miller, 1980; Macey et al., 1997).

Irrespective of the duplication mechanism random loss can easily be explained by the accumulation of deleterious mutations in one of the copies of duplicated genes. Selection pressure on the size of the mitogenomic DNA will then rapidly remove the non-functional pseudogene. Remnants of such pro- 
cesses have been detected for instance as non-coding regions at positions where the deleted genes would be expected (Arndt and Smith, 1998) or as pseudogenes (Macey et al., 1997). Recently a large scale study on tRNAs provided numerous examples of pseudogenisation supporting duplication and inverse duplication based mechanisms (Jühling et al., 2012a). The presence of multiple functional copies after a duplication can facilitate tRNA recruitment, i.e. the change of the identity of a tRNA due to point mutations in the anticodon. Several recruitment events affecting the mitochondrial leucine tRNAs have been reconstructed for the metazoan evolution (Higgs et al., 2003; Rawlings et al., 2003). Within the demosponges this phenomenon seems to be particularly frequent (Lavrov and Lang, 2005; Wang and Lavrov, 2011). This is phenomenon may lead to apparent rearrangements when tRNA identity and homology are used synonymously. This effect should be taken into account in the context of annotation (e.g. Dowton and Austin, 1999).

Inversions may be the result of intra-mitochondrial recombination (Dowton and Campbell, 2001; Lunt and Hyman, 1997). This mechanism may also lead to the formation of mini-circles (Dowton and Austin, 1999) and might also account for the heterogeneous gene contents observed in some clades, see Section 2.2. The mechanisms discussed above that can generate inverted duplicated segments, i.e. illegitimate recombination and head-to-head dimerisation, can be regarded as special cases producing apparent inversions of gene order.

Rearrangements often involve the replication origins (e.g. San Mauro et al., 2006), but also other hot spots of rearrangements have been described in the literature (Dowton and Austin, 1999). Based on the sparse species sampling available in early studies of mitogenomic rearrangements, tRNAs have been found to be involved more frequently in rearrangements than proteins and rRNAs (Wolstenholme, 1992; Macey et al., 1997). With the availability of a better species sampling and improved automatic methods for the comparison of mitochondrial gene orders (reviewed in Bernt et al., 2012a, in this special issue) large scale analyses on the properties of gene order evolution of mitogenomes have become possible. Case studies such as the manual analysis of Hymenoptera 
(Dowton et al., 2009) and two computational analyses of metazoan gene orders (Miklós and Hein, 2005; Bernt and Middendorf, 2011) confirm the conclusions of earlier studies and provide a more detailed quantitative picture of mitogenome rearrangements.

Less than $30 \%$ of the hymenopteran rearrangements are inversions, the majority being transpositions (Dowton et al., 2009). The 1:2 ratio of inversions to transpositions reported in (Miklós and Hein, 2005) may be due to the inclusion of the Deuterostomia or due to multiple counting of the same unique rearrangement. The extensive data set in (Bernt and Middendorf, 2011) allowed the most detailed analysis published so far. Slightly more than half of the reconstructed rearrangements have been found in non-chordates, but a considerable number of non-chordate rearrangements could not be reconstructed due to highly diverged gene orders. The detailed analysis of the reconstructed rearrangements in Protostomia in (Bernt and Middendorf, 2011) has shown 20\% inversions, more that $55 \%$ transposition, and more that $10 \%$ each of inverse transpositions and TDRLs, respectively. Similar rearrangement frequencies have been observed in the reconstructed rearrangements of Metazoa. More that 3/4 of the rearrangements affect only tRNAs. In the vast majority of these cases, only a single tRNA is affected.

It is important to note that rearrangement rates are not only unevenly distributed within the genome, where clear hot spots can be identified, but also taxonomically non-uniform. While for some taxa, such as Chordata, only a few, similar gene orders are known, a different gene order is found for virtually every sequenced mitogenome in other clades. Multiple recent duplications have been described for some geckos (Fujita et al., 2007). The heavily rearranged gene orders of Ascidia form another counterexample to the generally preserved gene order of deuterostomes (Gissi et al., 2010). Increased rearrangement rates were reported also for some insects (Shao et al., 2001) and within Mollusca (Grande et al., 2008). Genome rearrangement rates and nucleotide substitution frequency are correlated (Shao et al., 2003; Xu et al., 2006). It is unclear at present, which one is cause and which one is effect. Parasitic life styles seems 
to have an accelerating effect on the mutation rates (Castro et al., 2002).

\section{Transcriptome}

The mitochondrial genome is transcribed by a specialised machinery using the monomeric RNA polymerase POLRMT and specific mitochondrial transcription factors (mtTFA and the paralogous proteins mtTFB1 and mtTFB2). Interestingly, POLRMT also exhibits promoter-independent activity dependent on DNA supercoiling (Fukuoh et al., 2009). For reviews of the protein machinery involved in regulating mitochondrial gene expression we refer to Gagliardi et al. (2004); Shutt and Shadel (2010).

The primary transcripts are polycistronic precursors. Nuclear regulatory factors influence transcription levels both at the stage of initiation and termination (Asin-Cayuela and Gustafsson, 2007; Scarpulla, 2008). In mammals, the two alternative heavy strand promoters as well as the light strand promoter are located in the D-loop, reviewed e.g. by Asin-Cayuela and Gustafsson (2007); Scarpulla (2008). They give rise to three primary transcripts. The HSP2 promoter within the $t R N A$-Phe generates a large transcript that terminates at the distal so-called D-TERM locus, containing a conserved A/T rich sequence motive immediately upstream of the $t R N A$-Phe gene (Camasamudram et al., 2003). The more abundant, shorter transcript starts at the HSP1 promoter upstream of the $t R N A$-Phe and encodes the two rRNAs and two tRNAs. It ends at proximal, so-called mt-TERM signal beyond the rrnL rRNA gene within the adjacent tRNA-Leu gene (Christianson and Clayton, 1986). Sequence box II, located in the D-loop, acts as a sequence-dependent termination element for transcription originating from the light strand promoter (Pham et al., 2006). This situation appears to be largely conserved throughout the vertebrates (Coucheron et al., 2011). The box II sequence itself is conserved at least throughout the mammals (Sbisá et al., 1997). In Drosophila, RNA synthesis starts at two promoters on the heavy $(\mathrm{H})$ strand and three on the light (L) strand, largely matching the alternating blocks of genes located on heavy and light strand, respectively 
(Berthier et al., 1986; Torres et al., 2009). Large-scale rearrangements of gene order thus should be expected to affect also the structure of the mitochondrial transcriptome.

The primary transcripts are processed into mature rRNA and mRNA by cleavage of the 5' and 3' termini of the mitochondrial tRNAs. This processing, which is known as the RNA punctuation model (Ojala et al., 1980), is mediated by RNase $\mathrm{P}$ and tRNase $\mathrm{Z}$ endonucleases, respectively (Levinger et al., 2004). When multiple tRNA genes are present, as between nad3 and nad5 in Drosophila, they are removed sequentially from the 3' end (Stewart and Beckenbach, 2009). In both vertebrates and Drosophila, all mature mitochondrial mRNAs are monocistronic except the two bicistronic nad4/nad $4 L$ and atp 8/atp6 messages. Although atp6 and atp 8 are found in adjacent positions in more than $90 \%$ of the sequenced mitogenomes, and in particular in nearly all Chordata and Arthropoda, there are many exceptions, in particular in Mollusca, Cnidaria, Nematoda, and Platyhelminthes. The mRNAs are typically polyadenylated (Bobrowicz et al., 2008), although non-poly(A) mRNAs are also detectable (Mercer et al., 2011). An interesting feature of mitochondrial mRNAs is that many of the stop codons are complete only by polyadenylation (7 in human, 6 in cod, and at least 4 in fruit fly) so that they completely lack 3'UTRs (Nagaike et al., 2005; Stewart and Beckenbach, 2009). This appears to be a very frequent phenomenon without a distinctive phylogenetic distribution according to the RefSeq annotation.

cox1 features a 3'UTR complementary to the adjacent tRNA-Ser, and some mRNAs have heterogeneous 3'UTRs depending on the cell type (Temperley et al., 2010). This situation is conserved with minor differences at least among vertebrates (Coucheron et al., 2011). 5'UTRs are absent in general. Deep sequencing has been used already to generate detailed maps of transcript ends and processing sites (Lopez Sanchez et al., 2011; Brzezniak et al., 2011). Results demonstrated that mRNA abundance is heavily regulated by post-transcriptional processes (Torres et al., 2009; Mercer et al., 2011) and established the presence of non-canonical processing products. These appear to be linked in particular 
to the secondary structure of the tRNAs since non-canonical processing sites are associated with clusters of RNA secondary structures within the mRNAs (Mercer et al., 2011).

Mitochondrial rRNAs are also polyadenylated or at least feature a few nonencoded adenosines - as in the case of the rrnS of Drosophila (Stewart and Beckenbach, 2009). Like bacterial rRNAs, they are modified by both methylation and pseudouridylation at highly conserved positions (Ofengand and Bakin, 1997). All mitochondrial tRNAs require the addition of CCA to their 3' terminus by the mitochondrial tRNA-nucleotidyl transferase (Nagaike et al., 2001). Then they are chemically modified to ensure their proper folding, recognition, and basepairing (Helm and Attardi, 2004; Messmer et al., 2009). Modifications of the anticodon stem, such as the hypermodified nucleoside 5-methylaminomethyl-2thiouridylate at position 34, create the "wobble-base" necessary to enable the recognition of multiple codons (Agris et al., 2007).

In addition to the canonical genes a variety of non-coding RNA species are present in mitochondria (Lung et al., 2006). Two distinctive species of short RNAs are produced downstream of the tRNA 5' and 3' processing sites (Mercer et al., 2011). A small control region specific polyadenylated RNA species (7S RNA) with unknown function (Ojala et al., 1981) originates from the Lstrand primary transcript. Rackham et al. (2011) report three long non coding RNAs (lncRNAs) in mouse mitochondria that appear to have a role in the regulation of mitochondrial gene expression. Regulated antisense transcripts as well as a curious inverted repeat covalently linked to the $\operatorname{rrnL}$ RNA were reported to distinguish normal from tumor cells in human (Burzio et al., 2009). The mitochondrial transcription machinery, finally, also generates the RNA primer needed for initiation of heavy strand DNA synthesis. To this end, in mammals, a G-quadruplex structure is utilised to prematurely terminate transcription from the L-strand promoter (Wanrooij et al., 2010). 


\section{Concluding remarks}

Since the characterisation of the human mitochondrial genome in 1981 further genome sequencing led to the fall of several dogmas concerning the uniformity of animal mitochondrial genomes. At present the large set of observations is consistent with the idea that marked gene loss and mtDNA compaction occurred during the emergence of multi cellular animals, but the pronounced compaction was not coincident with the origin of the Metazoa. The best living surrogate for the ancestral metazoan mitochondrial genome is the placozoan genomes, which combine both, characteristics from protozoans and metazoans. An evolutionary speciality is found in derived cnidarians, which have linearised their mitochondrial genomes. All bilaterian mitochondrial genomes are widely conserved with respect to size, gene structure and content. Particularly here the study of differences in gene arrangement and genetic codes provides a large, not yet fully explored repertoire of phylogenetic markers. Although mitochondrial genomes in diploblastic and triploblastic animals have taken different routes and likely evolved in parallel, their source as a rich repertoire of informative phylogenetic markers applies to both lineages.

\section{Acknowledgements}

This work was supported by the German Research Foundation (DFG) through the project "Deep Metazoan Phylogeny" within SPP 1174 (projects STA 850/32, STA 850/2).

\section{References}

Abascal, F., Posada, D., Zardoya, R., 2012. The evolution of the mitochondrial genetic code in arthropods revisited. Mitochondr DNA 23, 84-91.

Agris, P. F., Vendeix, F. A., Graham, W. D., 2007. tRNA's wobble decoding of the genome: 40 years of modification. J Mol Biol 366, 1-13. 
Alfonzo, J. D., Söll, D., 2009. Mitochondrial tRNA import-the challenge to understand has just begun. Biol Chem 390, 717-722.

Anderson, S., Bankier, A. T., Barrell, B. G., de Bruijn, M. H. L., Coulson, A. R., Drouin, J., Eperon, I. C., Nierlich, D. P., Roe, B. A., Sanger, F., Schreier, P. H., Smith, A. J. H., Staden, R., Young, I. G., 1981. Sequence and organization of the human mitochondrial genome. Nature 290, 457-465.

Armstrong, M. R., Blok, V. C., Phillips, M. S., 2000. A multipartite mitochondrial genome in the potato cyst nematode Globodera pallida. Genetics 154, 181-192.

Arndt, A., Smith, M. J., 1998. Mitochondrial gene rearrangement in the sea cucumber genus Cucumaria. Mol Biol Evol 15 (8), 9-16.

Asakawa, S., Himeno, H., Miura, K., Watanabe, K., 1995. Nucleotide sequence and gene organization of the starfish Asterina pectinifera mitochondrial genome. Genetics 140 (3), 1047-1060.

Asin-Cayuela, J., Gustafsson, C. M., 2007. Mitochondrial transcription and its regulation in mammalian cells. Trends Biochem Sci 32, 111-117.

Bazin, E., Glémin, S., Galtier, N., 2006. Population size does not influence mitochondrial genetic diversity in animals. Science 312, 570-572.

Beagley, C. T., Okada, N. A., Wolstenholme, D. R., 1996. Two mitochondrial group I introns in a metazoan, the sea anemone Metridium senile: one intron contains genes for subunits 1 and 3 of NADH dehydrogenase. Proc Natl Acad Sci USA 93 (11), 5619-5623.

Beckenbach, A. T., Robson, S. K., Crozier, R. H., 2005. Single nucleotide +1 frameshifts in an apparently functional mitochondrial cytochrome b gene in ants of the genus Polyrhachis. J Mol Evol 60, 141-152.

Bendich, A. J., 2010. The end of the circle for yeast mitochondrial DNA. Mol Cell 39, 831-832. 
Bernt, M., Braband, A., Middendorf, M., Misof, B., Rota-Stabelli, O., Stadler, P. F., 2012a. Bioinformatics methods for the comparative analysis of metazoan mitochondrial genome sequences. Mol Phylog EvolDoi: 10.1016/j.ympev.2012.09.019.

Bernt, M., Donath, A., Jühling, F., Externbrink, F., Florentz, C., Fritzsch, G., Pütz, J., Middendorf, M., Stadler, P. F., 2012b. MITOS: Improved de novo metazoan mitochondrial genome annotation. Mol Phylog EvolDoi: 10.1016/j.ympev.2012.08.023.

Bernt, M., Middendorf, M., 2011. A method for computing an inventory of metazoan mitochondrial gene order rearrangements. BMC Bioinformatics 12 (Suppl 9), S6.

Berthier, F., Renaud, M., Alziari, S., Durand, R., 1986. RNA mapping on Drosophila mitochondrial DNA: precursors and template strands. Nucleic Acids Res 14, 4519-4533.

Bilewitch, J. P., Degnan, S. M., 2011. A unique horizontal gene transfer event has provided the octocoral mitochondrial genome with an active mismatch repair gene that has potential for an unusual self-contained function. BMC Evol Biol 11, 228.

Bobrowicz, A. J., Lightowlers, R. N., Chrzanowska-Lightowlers, Z., 2008. Polyadenylation and degradation of mRNA in mammalian mitochondria: a missing link? Biochem Soc Trans 36, 517-519.

Bogenhagen, D. F., 1999. DNA repair ???99: repair of mtDNA in vertebrates. Am J Hum Genet 64, 1276-1281.

Bogenhagen, D. F., Wang, Y., Shen, E. L., Kobayashi, R., 2003. Protein components of mitochondrial DNA nucleoids in higher eukaryotes. Mol Cell Proteomics 2, 1205-1216.

Bolden, A., Noy, G. P., Weissbach, A., 1977. DNA polymerase of mitochondria is a gamma-polymerase. J Biol Chem 252, 3351-3356. 
Boore, J. L., 1999. Animal mitochondrial genomes. Nucleic Acids Res 27, 17671780.

Boore, J. L., 2000. The duplication/random loss model for gene rearrangement exemplified by mitochondrial genomes of deuterostome animals. In: Sankoff, D., Nadeau, J. H. (Eds.), Comparative Genomics: Empirical and Analytical Approaches to Gene Order Dynamics, Map Alignment and the Evolution of Gene Families. Vol. 1 of Computational Biology Series. Kluwer Academic Publishers, pp. 133-147.

Boore, J. L., 2006. The complete sequence of the mitochondrial genome of Nautilus macromphalus (Mollusca: Cephalopoda). BMC Genomics 7, 182.

Boore, J. L., Lavrov, D. V., Brown, W. M., 1998. Gene translocation links insects and crustaceans. Nature 392, 667-668.

Bourlat, S. J., Nielsen, C., Economou, A. D., Telford, M. J., 2008. Testing the new animal phylogeny: a phylum level molecular analysis of the animal kingdom. Mol Phylogenet Evol 49, 23-31.

Bowmaker, M., Yang, M. Y., Yasukawa, T., Reyes, A., Jacobs, H. T., Huberman, J. A., Holt, I. J., 2003. Mammalian mitochondrial DNA replicates bidirectionally from an initiation zone. J Biol Chem 278 (51), 50961-50969.

Braband, A., Cameron, S. L., Podsiadlowski, L., Daniels, S. R., Mayer, G., 2010. The mitochondrial genome of the onychophoran Opisthopatus cinctipes (Peripatopsidae) reflects the ancestral mitochondrial gene arrangement of $\mathrm{Pa}-$ narthropoda and Ecdysozoa. Mol. Phylogenet. Evol. 57, 285-292.

Breton, S., Beaupré, H. D., Stewart, D. T., Piontkivska, H., Karmakar, M., Bogan, A. E., Blier, P. U., Hoeh, W. R., 2009. Comparative mitochondrial genomics of freshwater mussels (Bivalvia: Unionoida) with doubly uniparental inheritance of mtDNA: Gender-specific open reading frames and putative origins of replication. Genetics 183 (4), 1575-1589. 
Breton, S., Stewart, D. T., Shepardson, S., Trdan, R. J., Bogan, A. E., Chapman, E. G., Ruminas, A. J., Piontkivska, H., Hoeh, W. R., 2010. Novel protein genes in animal mtDNA: A new sex determination system in freshwater mussels (Bivalvia: Unionoida)? Mol Biol Evol 28, 1645-1659.

Broughton, R. E., Dowling, T. E., 1997. Evolutionary dynamics of tandem repeats in the mitochondrial DNA control region of the minnow Cyprinella spiloptera. Mol Biol Evol 14, 1187-1196.

Brown, G. G., Simpson, M. V., 1982. Novel features of animal mtDNA evolution as shown by sequences of two rat cytochrome oxidase subunit II genes. Proc Natl Acad Sci USA 79, 3246-3250.

Brown, T. A., Cecconi, C., Tkachuk, A. N., Bustamante, C., Clayton, D. A., 2005. Replication of mitochondrial DNA occurs by strand displacement with alternative light-strand origins, not via a strand-coupled mechanism. Gene Dev 19, 2466-2476.

Brown, W. M., George Jr, M., Wilson, A. C., 1979. Rapid evolution of animal mitochondrial DNA. Proc Natl Acad Sci USA 76, 1967-1971.

Brzezniak, L. K., Bijata, M., Szczesny, R. J., Stepien, P. P., 2011. Involvement of human ELAC2 gene product in 3' end processing of mitochondrial tRNAs. RNA Biol 8, 616-626.

Burger, G., Forget, L., Zhu, Y., Gray, M. W., Lang, B. F., 2003. Unique mitochondrial genome architecture in unicellular relatives of animals. Proc Natl Acad Sci USA 100, 892-897.

Burger, G., Yan, Y., Javadi, P., Lang, B. F., 2009. Group I-intron trans-splicing and mRNA editing in the mitochondria of placozoan animals. Trends Genet $25,381-386$.

Burzio, V. A., Villota, C., Villegas, J., Landerer, E., Boccardo, E., Villa, L. L., Martínez, R., Lopez, C., Gaete, F., Toro, V., Rodriguez, X., Burzio, L. O., 
2009. Expression of a family of noncoding mitochondrial RNAs distinguishes normal from cancer cells. Proc Natl Acad Sci USA 106, 9430-9434.

Calos, M. P., Miller, J. H., 1980. Transposable elements. Cell 20, 579-595.

Camasamudram, V., Fang, J. K., Avadhani, N. G., 2003. Transcription termination at the mouse mitochondrial $\mathrm{H}$-strand promoter distal site requires an A/T rich sequence motif and sequence specific DNA binding proteins. Eur J Biochem 270, 1128-1140.

Cameron, S. L., Yoshizawa, K., Mizukoshi, A., Whiting, M. F., Johnson, K. P., 2011. Mitochondrial genome deletions and minicircles are common in lice (insecta: Phthiraptera). BMC Genomics 12, 394.

Castellana, S., Vicario, S., Saccone, C., 2011. Evolutionary patterns of the mitochondrial genome in Metazoa: exploring the role of mutation and selection in mitochondrial protein coding genes. Genome Biol Evol. 3, 1067-1079.

Castora, F. J., Simpson, M. V., 1979. Search for a DNA gyrase in mammalian mitochondria. J Biol Chem 254, 11193-11195.

Castro, L. R., Austin, A. D., Dowton, M., 2002. Contrasting rates of mitochondrial molecular evolution in parasitic Diptera and Hymenoptera. Mol Biol Evol 19 (7), 1100-1113.

Chacinska, A., Koehler, C. M., Milenkovic, D., Lithgow, T., Pfanner, N., 2009. Importing mitochondrial proteins: Machineries and mechanisms. Cell 138 (4), 628-644.

Chang, D. D., Hauswirth, W. W., Clayton, D. A., 1985. Replication priming and transcription initiate from precisely the same site in mouse mitochondrial DNA. EMBO J 4, 1559-1567.

Chen, J. M., Chuzhanova, N., Stenson, P. D., Ferec, C., Cooper, D. N., 2005. Meta-analysis of gross insertions causing human genetic disease: novel mutational mechanisms and the role of replication slippage. Hum Mutat 25, $207-221$. 
Christianson, T. W., Clayton, D. A., 1986. In vitro transcription of human mitochondrial DNA: accurate termination requires a region of DNA sequence that can function bidirectionally. Proc Natl Acad Sci USA 83, 6277-6281.

Clayton, D., 2003. Mitochondrial DNA replication: What we know. IUBMB Life 55, 213-217.

Clayton, D. A., 1982. Replication of animal mitochondrial DNA. Cell 28, 693705.

Coucheron, D. H., Nymark, M., Breines, R., Karlsen, B. O., Andreassen, M., Jørgensen, T. E., Moum, T., Johansen, S. D., 2011. Characterization of mitochondrial mRNAs in codfish reveals unique features compared to mammals. Curr Genet 57, 213-222.

Crease, T. J., 1999. The complete sequence of the mitochondrial genome of Daphnia pulex (Cladocera: Crustacea). Gene 233 (1-2), 89-99.

Curtis, B. A., Archibald, J. M., 2010. A spliceosomal intron of mitochondrial DNA origin. Curr Biology 20, R919-R920.

Dellaporta, S. L., Xu, A., Sagasser, S., Jakob, W., Moreno, M. A., Buss, L. W., Schierwater, B., 2006. Mitochondrial genome of Trichoplax adhaerens supports Placozoa as the basal lower metazoan phylum. Proc Natl Acad Sci USA $103,8751-8756$.

Dörner, M., Altmann, M., Pääbo, S., Mörl, M., 2001. Evidence for import of a lysyl-tRNA into marsupial mitochondria. Mol. Biol. Cell 12, 2688-2698.

Doucet-Beaupré, H., Breton, S., Chapman, E. G., Blier, P. U., Bogan, A. E., Stewart, D. T., Hoeh, W. R., 2010. Mitochondrial phylogenomics of the Bivalvia (Mollusca): searching for the origin and mitogenomic correlates of doubly uniparental inheritance of mtDNA. BMC Evol Biol 10, 50.

Dowton, M., Austin, A. D., 1999. Evolutionary dynamics of a mitochondrial rearrangement "hot spot" in the Hymenoptera. Mol Biol Evol 16, 298-309. 
Dowton, M., Cameron, S. L., Dowavic, J. I., Austin, A. D., Whiting, M., 2009. Characterization of 67 mitochondrial tRNA gene rearrangements in the hymenoptera suggests that mitochondrial tRNA gene position is selectively neutral. Mol Biol Evol 26, 1607-1617.

Dowton, M., Campbell, N. J., 2001. Intramitochondrial recombination - is it why some mitochondrial genes sleep around? Trends Ecol Evol 16, 269-271.

Eitel, M., Schierwater, B., 2010. The phylogeography of the Placozoa suggests a taxon rich phylum in tropical and subtropical waters. Mol Ecology 19, 23152327.

Ender, A., Schierwater, B., 2003. Placozoa are not derived cnidarians: Evidence from molecular morphology. Mol Biol Evol 20, 130-134.

Erpenbeck, D., Voigt, O., Wörheide, G., V, L. D., 2009. The mitochondrial genomes of sponges provide evidence for multiple invasions by Repetitive Hairpin-forming Elements (RHE). BMC Genomics 10, 591.

Fernández-Silva, P., Enriquez, J. A., Montoya, J., 2003. Replication and transcription of mammalian mitochondrial DNA. Exp Physiology 88, 41-56.

Fish, J., Raule, N., Attardi, G., 2004. Discovery of a major D-Loop replication origin reveals two modes of human mtDNA synthesis. Science 306, 2098-2101.

Fujita, M. K., Boore, J. L., Moritz, C., 2007. Multiple origins and rapid evolution of duplicated mitochondrial genes in parthenogenetic geckos (Heteronotia binoei; Squamata, Gekkonidae). Mol Biol and Evol 24, 2775-2786.

Fukami, H., Chen, C., Chiou, C.-Y., Knowlton, N., 2007. Novel group I introns encoding a putative homing endonuclease in the mitochondrial cox1 gene of scleractinian corals. J Mol Evol 64, 591-600.

Fukuoh, A., Ohgaki, K., Hatae, H., Kuraoka, I., Aoki, Y., Uchiumi, T., Jacobs, H. T., Kang, D., 2009. DNA conformation-dependent activities of human mitochondrial RNA polymerase. Genes Cells 14, 1029-1042. 
Gagliardi, D., Stepien, P. P., Temperley, R. J., Lightowlers, R. N., ChrzanowskaLightowlers, Z. M., 2004. Messenger RNA stability in mitochondria: different means to an end. Trends Genet 20, 260-267.

Gazave, E., Lapebie, P., Renard, E., Vacelet, J., Rocher, C., Ereskovsky, A. V., Lavrov, D. V., Borchiellini, C., 2010. Molecular phylogeny restores the suprageneric subdivision of homoscleromorph sponges (Porifera, Homoscleromorpha). PLoS ONE 5, e14290.

Gissi, C., Iannelli, F., Pesole, G., 2008. Evolution of the mitochondrial genome of metazoa as exemplified by comparison of congeneric species. Heredity 101, 301-320.

Gissi, C., Pesole, G., Mastrototaro, F., Iannelli, F., Guida, V., Griggio, F., 2010. Hypervariability of ascidian mitochondrial gene order: Exposing the myth of deuterostome organelle genome stability. Mol Biol Evol 27 (2), 211-215.

Goddard, J. M., Wolstenholme, D. R., 1980. Origin and direction of replication in mitochondrial DNA molecules from the genus Drosophila. Nucleic Acids Res 8, 741-757.

Goddard, M. R., Leigh, J., Roger, A. J., Pemberton, A. J., 2006. Invasion and persistence of a selfish gene in the Cnidaria. PLoS ONE 1, e3.

Grande, C., Templado, J., Zardoya, R., 2008. Evolution of gastropod mitochondrial genome arrangements. BMC Evol Biol 8, 61.

Gredilla, R., 2011. DNA damage and base excision repair in mitochondria and their role in aging. J. Aging Res. 2011, 257093.

Haen, K. M., Pett, W., Lavrov, D. V., 2010. Parallel loss of nuclear-encoded mitochondrial aminoacyl-tRNA synthetases and mtDNA-encoded tRNAs in Cnidaria. Mol. Biol. Evol. 27, 2216-2219.

Harman, D., 1972. A biologic clock: the mitochondria? J Am Geriatr Soc 20, 145-147. 
Hassanin, A., Lger, N., Deutsch, J., 2005. Evidence for multiple reversals of asymmetric mutational constraints during the evolution of the mitochondrial genome of Metazoa, and consequences for phylogenetic inferences. Syst Biol $54,277-298$.

Hazkani-Covo, E., 2009. Mitochondrial insertions into primate nuclear genomes suggest the use of numts as a tool for phylogeny. Mol Biol Evol 26, 2175-2179.

Hazkani-Covo, E., Graur, D., 2007. A comparative analysis of numt evolution in human and chimpanzee. Mol Biol Evol 24, 13-18.

Hazkani-Covo, E., Zeller, R., Martin, W., 2010. Molecular poltergeists: Mitochondrial DNA copies (numts) in sequenced nuclear genomes. PLoS Genet 6, e1000834.

Hehman, G. L., Hauswirth, W. W., 1992. DNA helicase from mammalian mitochondria. Proc Natl Acad Sci USA 89, 8562-8566.

Helfenbein, K. G., Fourcade, H. M., Vanjani, R. G., Boore, J. L., 2004. The mitochondrial genome of Paraspadella gotoi is highly reduced and reveals that chaetognaths are a sister group to protostomes. Proc Natl Acad Sci USA 101, 10639-10643.

Helm, M., 2006. Post-transcriptional nucleotide modification and alternative folding of RNA. Nucleic Acids Res. 34, 721-733.

Helm, M., Attardi, G., 2004. Nuclear control of cloverleaf structure of human

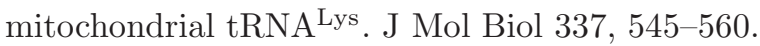

Higgs, P. G., Jameson, D., Jow, H., Rattray, M., 2003. The evolution of $t R N A$ Leu genes in animal mitochondrial genomes. J Mol Evol 57, 435-445.

Holt, I. J., Lorimer, H. E., Jacobs, H. T., 2000. Coupled leading- and laggingstrand synthesis of mammalian mitochondrial DNA. Cell 100, 515-524.

Huynen, M., 2010. Mosaic origin of the mitochondrial proteome. Proteomics 10, 4012-4024. 
Jühling, F., Pütz, J., Bernt, M., Donath, A., Middendorf, M., Florentz, C., Stadler, P. F., 2012a. Improved systematic tRNA gene annotation allows new insights into the evolution of mitochondrial tRNA structures and into the mechanisms of mitochondrial genome rearrangements. Nucleic Acids Res 40, $2833-2845$.

Jühling, F., Pütz, J., Florentz, C., Stadler, P. F., 2012b. Armless mitochondrial tRNAs in Enoplea (Nematoda). RNA Biology 9, 1161-1166.

Kayal, E., Bentlage, B., Collins, A. G., Kayal, M., Pirro, S., Lavrov, D. V., 2012. Evolution of linear mitochondrial genomes in medusozoan cnidarians. Genome Biol Evol 4, 1-12.

Kayal, E., Lavrov, D. V., 2008. The mitochondrial genome of Hydra oligactis (Cnidaria, Hydrozoa) sheds new light on animal mtDNA evolution and cnidarian phylogeny. Gene 410, 177-186.

Kilpert, F., Podsiadlowski, L., 2006. The complete mitochondrial genome of the common sea slater, Ligia oceanica (Crustacea, Isopoda) bears a novel gene order and unusual control region features. BMC Genomics 7, 241.

Kleine, T., Maier, U. G., Leister, D., 2009. DNA transfer from organelles to the nucleus: The idiosyncratic genetics of endosymbiosis. Annu Rev Plant Biol $60,115-138$

Kohn, A. B., Citarella, M. R., Kocot, K. M., Bobkova, Y. V., Halanych, K. M., Moroz, L. L., 2011. Rapid evolution of the compact and unusual mitochondrial genome in the ctenophore, Pleurobrachia bachei. Mol Phylog Evol 63, 203207.

Kosovsky, M. J., Soslau, G., 1993. Immunological identification of human platelet mitochondrial DNA topoisomerase I. Biochim Biophys Acta 1164, 101-107. 
Krishnan, N. M., Seligmann, H., Raina, S. Z., Pollock, D. D., 2004. Detecting gradients of asymmetry in site-specific substitutions in mitochondrial genomes. DNA Cell Biol 23, 707-714.

Lavrov, D. V., 2010. Rapid proliferation of repetitive palindromic elements in mtDNA of the endemic baikalian sponge Lubomirskia baicalensis. Mol Biol Evol 27, 757-760.

Lavrov, D. V., Boore, J. L., Brown, W. M., 2002. Complete mtDNA sequences of two millipedes suggest a new model for mitochondrial gene rearrangements: Duplication and nonrandom loss. Mol Biol Evol 19, 163-169.

Lavrov, D. V., Brown, W. M., 2001. Trichinella spiralis mtDNA: A nematode mitochondrial genome that encodes a putative ATP8 and normally structured tRNAs and has a gene arrangement relatable to those of coelomate metazoans. Genetics 157, 621-637.

Lavrov, D. V., Lang, B. F., 2005. Transfer RNA gene recruitment in mitochondrial DNA. Trends Genet 21, 129-133.

Levinger, L., Mörl, M., Florentz, C., 2004. Mitochondrial tRNA 3' end metabolism and human disease. Nucleic Acids Res 32, 5430-5441.

Lopez Sanchez, M. I., Mercer, T. R., Davies, S. M., Shearwood, A. M., Nygård, K. K., Richman, T. R., Mattick, J. S., Rackham, O., Filipovska, A., 2011. RNA processing in human mitochondria. Cell Cycle 10, 2904-2916.

Lung, B., Zemann, A., Madej, M. J., Schuelke, M., Techritz, S., Ruf, S., Bock, R., Hüttenhofer, A., 2006. Identification of small non-coding RNAs from mitochondria and chloroplasts. Nucleic Acids Res 34, 3842-3852.

Lunt, D. H., Hyman, B. C., 1997. Animal mitochondrial DNA recombination. Nature 387, 247.

Macey, J. R., Larson, A., Ananjeva, N. B., Fang, Z., Papenfuss, T. J., 1997. Two novel gene orders and the role of light-strand replication in rearrangement of the vertebrate mitochondrial genome. Mol Biol Evol 14, 91-104. 
Martens, P. A., Clayton, D. A., 1979. Mechanism of mitochondrial DNA replication in mouse L-cells: Localization and sequence of the light-strand origin of replication. J Mol Biol 135 (2), 327-351.

McBride, H. M., Neuspiel, M., Wasiak, S., 2006. Mitochondria: More than just a powerhouse. Curr Biol 16, R551-560.

McFadden, C. S., France, S. C., Sánchez, J. A., Alderslade, P., 2006. A molecular phylogenetic analysis of the Octocorallia (Cnidaria: Anthozoa) based on mitochondrial protein-coding sequences. Mol Phyl Evol 41, 513-527.

Medina, M., Collins, A. G., Takaoka, T. L., Kuehl, J. V., Boore, J. L., 2006. Naked corals: Skeleton loss in Scleractinia. Proc Natl Acad Sci USA 103, 9096-9100.

Meiklejohn, C. D., Montooth, K. L., Rand, D. M., 2007. Positive and negative selection on the mitochondrial genome. Trends Genet. 23, 259-263.

Mercer, T. R., Neph, S., Dinger, M. E., Crawford, J., Smith, M. A., Shearwood, A. M., Haugen, E., Bracken, C. P., Rackham, O., Stamatoyannopoulos, J. A., Filipovska, A., Mattick, J. S., 2011. The human mitochondrial transcriptome. Cell 146, 645-658.

Messmer, M., Pütz, J., Suzuki, T., Sauter C, Sissler, M., Florentz, C., 2009. Tertiary network in mammalian mitochondrial tRNA ${ }^{\text {Asp }}$ revealed by solution probing and phylogeny. Nucleic Acids Res 37, 6881-6895.

Miklós, I., Hein, J., 2005. Genome rearrangement in mitochondria and its computational biology. In: Comparative Genomics, RECOMB 2005 International Workshop, RCG 2005, Proceedings. Vol. 3388 of Lecture Notes in Computer Science. Springer, pp. 85-96.

Milbury, C., Gaffney, P., 2005. Complete mitochondrial DNA sequence of the eastern oyster Crassostrea virginica. Marine Biotechnology 7, 697-712. 
Milbury, C. A., Lee, J., Cannone, J. J., Gaffney, P. M., Gutell, R. R., 2010. Fragmentation of the large subunit ribosomal RNA gene in oyster mitochondrial genomes. BMC Genomics 11, 485.

Min, X. J., Hickey, D. A., 2007. DNA asymmetric strand bias affects the amino acid composition of mitochondrial proteins. DNA Res 14 (5), 201-206.

Mindell, D. P., Sorenson, M. D., Dimcheff, D. E., 1998. An extra nucleotide is not translated in mitochondrial ND3 of some birds and turtles. Mol Biol Evol $15,1568-1571$.

Mueller, R. L., Boore, J. L., 2005. Molecular mechanisms of extensive mitochondrial gene rearrangement in plethodontid salamanders. Mol Biol Evol 22, 2104-2112.

Muller, H. J., 1964. The relation of recombination to mutational advance. Mutat Res 1, 2-9.

Nagaike, T., Suzuki, T., Katoh, T., Ueda, T., 2005. Human mitochondrial mRNAs are stabilized with polyadenylation regulated by mitochondriaspecific poly(A) polymerase and polynucleotide phosphorylase. J Biol Chem 280, 19721-19727.

Nagaike, T., Suzuki, T., Tomari, Y., Takemoto-Hori, C., Negayama, F., Watanabe, K., Ueda, T., 2001. Identification and characterization of mammalian mitochondrial tRNA nucleotidyltransferases. J Biol Chem 276, 40041-40049.

Nosek, J., Tomáška, L., 2003. Mitochondrial genome diversity: evolution of the molecular architecture and replication strategy. Current Genetics 44, 73-84.

Ofengand, J., Bakin, A., 1997. Mapping to nucleotide resolution of pseudouridine residues in large subunit ribosomal RNAs from representative eukaryotes, prokaryotes, archaebacteria, mitochondria and chloroplasts. J Mol Biol 266, 246-268. 
Ojala, D., Crews, S., Montoya, J., Gelfand, R., Attardi, G., 1981. A small polyadenylated RNA (7 S RNA), containing a putative ribosome attachment site, maps near the origin of human mitochondrial DNA replication. J Mol Biol 150, 303-314.

Ojala, D., Merkel, C., Gelfand, R., Attardi, G., 1980. The tRNA genes punctuate the reading of genetic information in human mitochondrial DNA. Cell $22,393-403$.

Pett, W., Ryan, J. F., Pang, K., Mullikin, J. C., Martindale, M., Baxevanis, A. D., Lavrov, D. V., 2011. Extreme mitochondrial evolution in the ctenophore Mnemiopsis leidyi: Insight from mtDNA and the nuclear genome. Mitochondrial DNA 22, 130-142.

Pham, X. H., Farge, G., Shi, Y., Gaspari, M., Gustafsson, C. M., Falkenberg, M., 2006. Conserved sequence box II directs transcription termination and primer formation in mitochondria. J Biol Chem 281, 24647-24652.

Podsiadlowski, L., Braband, A., Mayer, G., 2008. The complete mitochondrial genome of the onychophoran Epiperipatus biolleyi reveals a unique transfer RNA set and provides further support for the ecdysozoa hypothesis. Mol Biol Evol 25, 42-51.

Pohjoismäki, J. L. O., Goffart, S., 2011. Of circles, forks and humanity: Topological organisation and replication of mammalian mitochondrial DNA. BioEssays $33,290-299$.

Pohjoismäki, J. L. O., Holmes, J. B., Wood, S. R., Yang, M.-Y., Yasukawa, T., Reyes, A., Bailey, L. J., Cluett, T. J., Goffart, S., Willcox, S., Rigby, R. E., Jackson, A. P., Spelbrink, J. N., Griffith, J. D., Crouch, R. J., Jacobs, H. T., Holt, I. J., 2011. Mammalian mitochondrial DNA replication intermediates are essentially duplex, but contain extensive tracts of RNA/DNA hybrid. J Mol Biol 397, 1144-1155. 
Popadin, K., Polishchuk, L. V., Mamirova, L., Knorre, D., Gunbin, K., 2007. Accumulation of slightly deleterious mutations in mitochondrial protein-coding genes of large versus small mammals. Proc Natl Acad Sci USA 104, 1339013395 .

Rackham, O., Shearwood, A. M., Mercer, T. R., Davies, S. M., Mattick, J. S., Filipovska, A., 2011. Long noncoding RNAs are generated from the mitochondrial genome and regulated by nuclear-encoded proteins. RNA 17, 2085-2093.

Raimond, R., Marcadé, I., Bouchon, D., Rigaud, T., Bossy, J.-P., Souty-Grosset, C., 1999. Organization of the large mitochondrial genome in the isopod Armadillidium vulgare. Genetics 151, 203-210.

Rawlings, T. A., Collins, T. M., Bieler, R., 2003. Changing identities: tRNA duplication and remolding within animal mitochondrial genomes. Proc Natl Acad Sci USA 100, 15700-15705.

Reyes, A., Gissi, C., Pesole, G., Saccone, C., 1998. Asymmetrical directional mutation pressure in the mitochondrial genome of mammals. Mol Biol Evol 15, 957-966.

Reyes, A., Yang, M. Y., Bowmaker, M., Holt, I. J., 2005. Bidirectional replication initiates at sites throughout the mitochondrial genome of birds. J Biol Chem 280, 3242-3250.

Robberson, D. L., Kasamatsu, H., Vinograd, J., 1972. Replication of mitochondrial DNA. Circular replicative intermediates in mouse L cells. Proc Natl Acad Sci USA 69 (3), 737-741.

Roberti, M., Musicco, C., Polosa, P. L., Gadaleta, M. N., Cantatore, P., 1996. DNA-helicase activity from sea urchin mitochondria. Biochem Bioph Res Co 219, 134-139.

Rot, C., Goldfarb, I., Ilan, M., Huchon, D., 2006. Putative cross-kingdom horizontal gene transfer in sponge (Porifera) mitochondria. BMC Evol Biol 6, 71. 
Russell, R., Beckenbach, A., 2008. Recoding of translation in turtle mitochondrial genomes: Programmed frameshift mutations and evidence of a modified genetic code. J Mol Evol 67, 682-695.

Saccone, C., Pesole, G., Sbisá, E., 1991. The main regulatory region of mammalian mitochondrial DNA: Structure-function model and evolutionary pattern. J Mol Evol 33, 83-91.

Saito, S., Tamura, K., Aotsuka, T., 2005. Replication origin of mitochondrial DNA in insects. Genetics 171, 1695-1705.

San Mauro, D., Gower, D. J., Zardoya, R., Wilkinson, M., 2006. A hotspot of gene order rearrangement by tandem duplication and random loss in the vertebrate mitochondrial genome. Mol Biol Evol 23, 227-234.

Santos, M. A. S., Moura, G., Massey, S. E., Tuite, M. F., 2004. Driving change: the evolution of alternative genetic codes. Trends Genet 20 (2), 95-102.

Satta, Y., Ishiwa, H., Chigusa, S. I., 1987. Analysis of nucleotide substitutions of mitochondrial DNAs in Drosophila melanogaster and its sibling species. Mol. Biol. Evol. 4, 638-650.

Sbisá, E., Tanzariello, F., Reyes, A., Pesole, G., Saccone, C., 1997. Mammalian mitochondrial D-loop region structural analysis: identification of new conserved sequences and their functional and evolutionary implications. Gene $205,125-140$.

Scarpulla, R. C., 2008. Transcriptional paradigms in mammalian mitochondrial biogenesis and function. Physiol Rev 88, 611-638.

Schierwater, B., 2005. My favorite animal, Trichoplax adhaerens. BioEssays 27, 1294-1302.

Segovia, R., Pett, W., Trewick, S., Lavrov, D. V., 2011. Extensive and evolutionarily persistent mitochondrial tRNA editing in velvet worms (phylum Onychophora). Mol. Biol. Evol. 28, 2873-2881. 
Shadel, G. S., Clayton, D. A., 1997. Mitochondrial DNA maintenance in vertebrates. Annu Rev Biochem 66, 409-435.

Shao, R., Barker, S. C., 2011. Chimeric mitochondrial minichromosomes of the human body louse, Pediculus humanus: evidence for homologous and nonhomologous recombination. Gene 473, 36-43.

Shao, R., Campbell, N. J. H., Schmidt, E. R., Barker, S. C., 2001. Increased rate of gene rearrangement in the mitochondrial genomes of three orders of hemipteroid insects. Mol Biol Evol 18 (9), 1828-1832.

Shao, R., Dowton, M., Murrell, A., Barker, S. C., 2003. Rates of gene rearrangement and nucleotide substitution are correlated in the mitochondrial genomes of insects. Mol Biol Evol 20 (10), 1612-1619.

Shao, R., Kirkness, E. F., Barker, S. C., 2009. The single mitochondrial chromosome typical of animals has evolved into 18 minichromosomes in the human body louse, Pediculus humanus. Genome Res 19, 904-912.

Shutt, T. E., Shadel, G. S., 2010. Inventory of the human mitochondrial gene expression machinery with links to disease. Environ Mol Mutagen 51, 360379.

Signorovitch, A. Y., Buss, L. W., Dellaporta, S. L., 2007. Comparative genomics of large mitochondria in placozoans. PLoS Genet 3, e13.

Song, H., Buhay, J. E., Whiting, M. F., Crandall, K. A., 2008. Many species in one: DNA barcoding overestimates the number of species when nuclear mitochondrial pseudogenes are coamplified. Proc Natl Acad Sci USA 105, $13486-13491$.

Stewart, J. B., Beckenbach, A. T., 2009. Characterization of mature mitochondrial transcripts in Drosophila, and the implications for the tRNA punctuation model in arthropods. Gene 445, 49-57. 
Suga, K., Welch, D. B. M., Tanaka, Y., Sakakura, Y., Hagiwara, A., 2008. Two circular chromosomes of unequal copy number make up the mitochondrial genome of the rotifer Brachionus plicatilis. Mol Biol Evol 25, 1129-1137.

Szitenberg, A., Rot, C., Ilan, M., Huchon, D., 2010. Diversity of sponge mitochondrial introns revealed by cox1 sequences of Tetillidae. BMC Evol Biol 10, 288.

Taanman, J.-W., 1999. The mitochondrial genome: structure, transcription, translation and replication. Biochim Biophys Acta - Bioenergetics 1410, 103123.

Temperley, R. J., Wydro, M., Lightowlers, R. N., Chrzanowska-Lightowlers, Z. M., 2010. Human mitochondrial mRNAs-like members of all families, similar but different. Biochim Biophys Acta 1797, 1081-1085.

Thrash, J. C., Boyd, A., Huggett, M. J., Grote, J., Carini, P., Yoder, R. J., Robbertse, B., Spatafora, J. W., Rappé, M. S., Giovannoni, S. J., 2011. Phylogenomic evidence for a common ancestor of mitochondria and the SAR11 clade. Scientific Reports 1, 13.

Tiranti, V., Rocchi, M., DiDonato, S., Zeviani, M., 1993. Cloning of human and rat cDNAs encoding the mitochondrial single-stranded DNA-binding protein (SSB). Gene 126, 219-225.

Torres, T. T., Dolezal, M., Schlötterer, C., Ottenwälder, B., 2009. Expression profiling of Drosophila mitochondrial genes via deep mRNA sequencing. Nucleic Acids Res 37, 7509-7518.

Vallès, Y., Halanych, K. M., Boore, J. L., 2008. Group II introns break new boundaries: Presence in a bilaterian's genome. PLoS ONE 3, e1488.

Viljakainen, L., Oliveira, D. C., Werren, J. H., Behura, S. K., 2010. Transfers of mitochondrial DNA to the nuclear genome in the wasp Nasonia vitripennis. Insect Mol Biol 19 Suppl 1, 27-35. 
Voigt, O., Erpenbeck, D., Wörheide, G., 2008. A fragmented metazoan organellar genome: the two mitochondrial chromosomes of Hydra magnipapillata. BMC Genomics 9, 350 .

Walberg, M. W., Clayton, D. A., 1981. Sequence and properties of the human KB cell and mouse L cell D-loop regions of mitochondrial DNA. Nucleic Acids Res 9, 5411-5421.

Wang, X., Lavrov, D. V., 2008. Seventeen new complete mtDNA sequences reveal extensive mitochondrial genome evolution within the Demospongiae. PLoS ONE 3, e2723.

Wang, X., Lavrov, D. V., 2011. Gene recruitment - a common mechanism in the evolution of transfer RNA gene families. Gene 475, 22-29.

Wanrooij, P. H., Uhler, J. P., Simonsson, T., Falkenberg, M., Gustafsson, C. M., 2010. G-quadruplex structures in RNA stimulate mitochondrial transcription termination and primer formation. Proc Natl Acad Sci USA 107, 16072-16077.

Watanabe, K., Yokobori, S.-i., 2011. tRNA modification and genetic code variations in animal mitochondria. J Nucleic Acids 2011, 623095.

Wei, S.-J., Shi, M., Chen, X.-X., Sharkey, M. J., van Achterberg, C., Ye, G.Y., He, J.-H., 2010. New views on strand asymmetry in insect mitochondrial genomes. PLoS ONE 5, e12708.

Wolstenholme, D. R., 1992. Animal mitochondrial DNA: Structure and evolution. Int Rev Cytol 141, 173-216.

Wolstenholme, D. R., Okimoto, R., Macfarlane, J. L., 1994. Nucleotide correlations that suggest tertiary interactions in the TV-replacement loop-containing mitochondrial tRNAs of the nematodes, Caenorhabditis elegans and Ascaris suum. Nucleic Acids Res 22, 4300-4306.

Wong, T. W., Clayton, D. A., 1986. DNA primase of human mitochondria is associated with structural RNA that is essential for enzymatic activity. Cell $45,817-825$. 
Xu, W., Jameson, D., Tang, B., Higgs, P., 2006. The relationship between the rate of molecular evolution and the rate of genome rearrangement in animal mitochondrial genomes. J Mol Evol 63, 375-392.

Yamazaki, N., Ueshima, R., Terrett, J. A., Yokobori, S. I., Kaifu, M., Segawa, R., Kobayashi, T., Numachi, K. I., Ueda, T., Nishikawa, K., Watanabe, K., Thomas, R. H., 1997. Evolution of pulmonate gastropod mitochondrial genomes: Comparisons of gene organizations of Euhadra, Cepaea and Albinaria and implications of unusual tRNA secondary structures. Genetics 145, $749-758$.

Yang, M. Y., Bowmaker, M., Reyes, A., Vergani, L., Angeli, P., Gringeri, E., Jacobs, H. T., Holt, I. J., 2002. Biased incorporation of ribonucleotides on the mitochondrial L-strand accounts for apparent strand-asymmetric DNA replication. Cell 111, 495-505.

Zardoya, R., Meyer, A., 1996. Phylogenetic performance of mitochondrial protein-coding genes in resolving relationships among vertebrates. Mol. Biol. Evol. 13, 933-942.

Zhang, D.-X., Hewitt, G. M., 1997. Insect mitochondrial control region: A review of its structure, evolution and usefulness in evolutionary studies. Biochem Syst Ecol 25, 99-120.

Zhong, M., Struck, T. H., Halanych, K. M., 2008. Phylogenetic information from three mitochondrial genomes of Terebelliformia (Annelida) worms and duplication of the methionine tRNA. Gene 416, 11-21. 


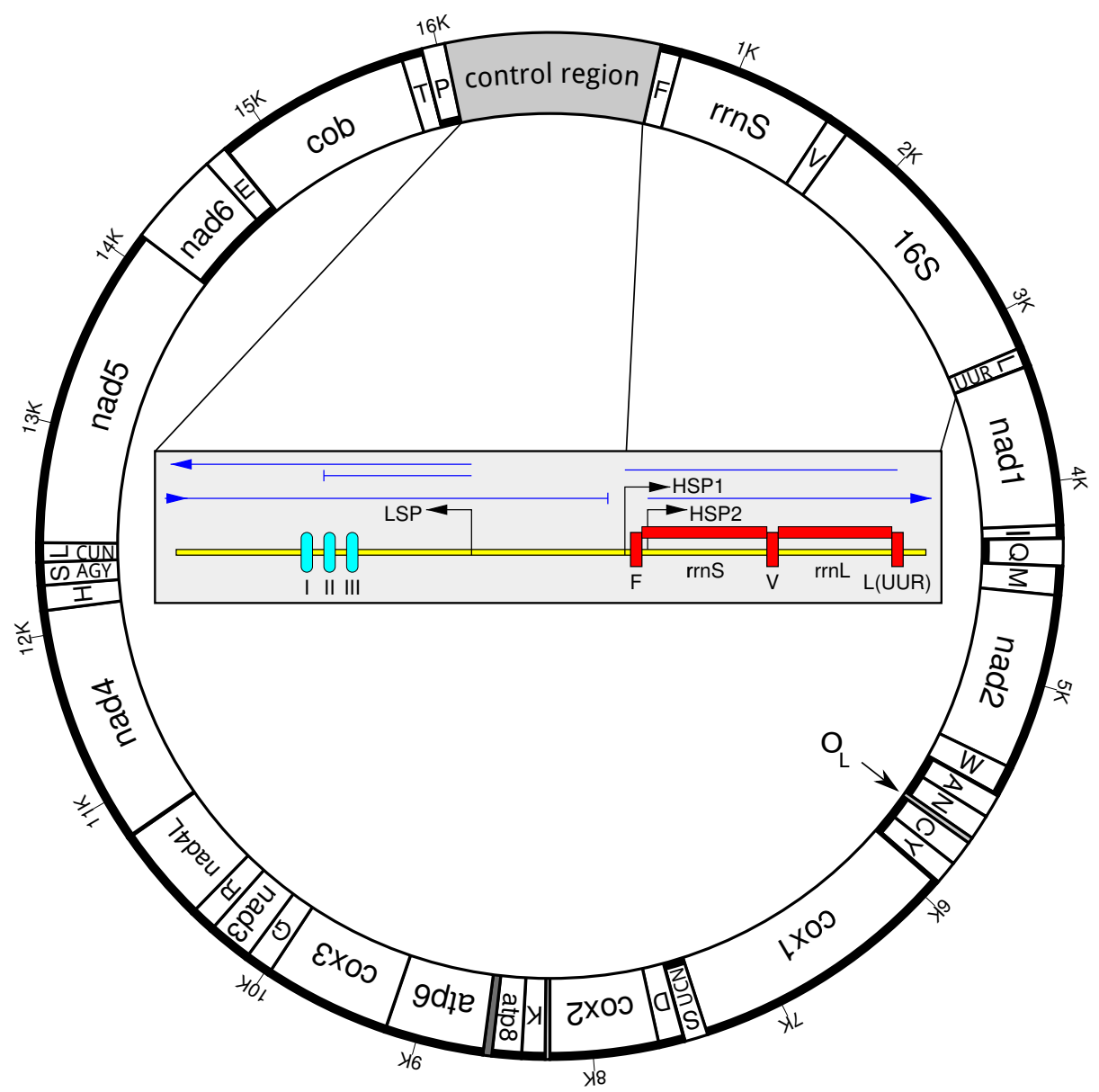

Figure 1: Representation of the human mitogenome which has the gene complement typical for metazoan mitogenomes; image generated with mtviz http://pacosy.informatik. uni-leipzig.de/mtviz/. The coding strand is indicated by think line; abbreviations are as in the text and for tRNAs the one letter code of the corresponding amino acid is given; for the leucine and serine tRNAs the recognised codon is indicated. The inset sketches the organisation of the control region. The three conserved sequence blocks (CSB) are marked I, II, and III. The primer for H-strand replication and the two H-strand transcripts are indicated. 
a)

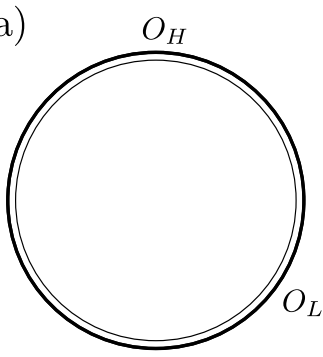

d)

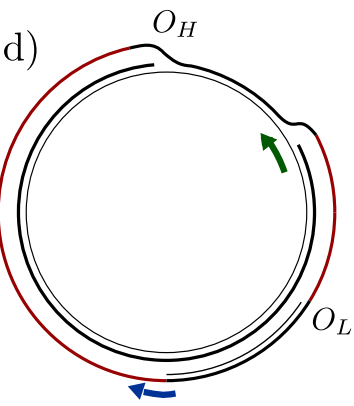

b)

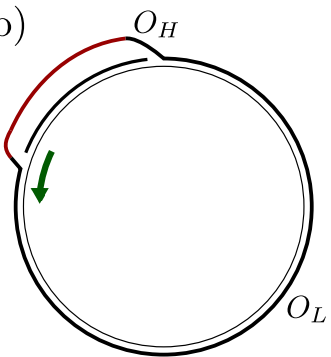

e)

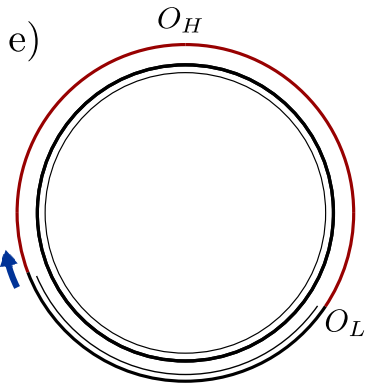

c)

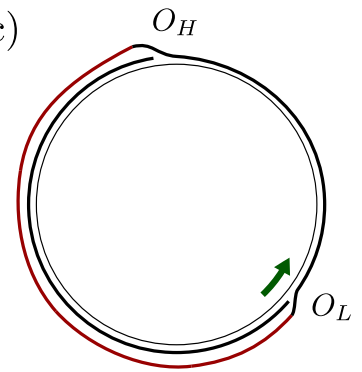

f)

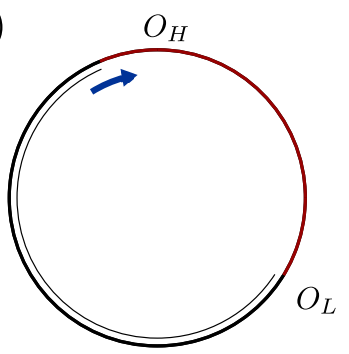

Figure 2: Representation of the strand-displacement model of replication; mitochondrial genome with replication origins $\approx$ as in human $(\mathrm{A})$; H-strand replication has been initiated at $O_{H}$ and proceeds towards $O_{L}(\mathrm{~A}, \mathrm{~B}) ; \mathrm{L}$-strand replication has been started (D); H-strand replication finishes and segregation $(\mathrm{E})$; the unfinished daughter replicate finished L-strand replication $(\mathrm{F})$; light and heavy strand are distinguished by line width; H-Strand replication is indicated by a green arrow and L-strand replication by a blue arrow; single stranded regions of the H-strand are highlighted in red

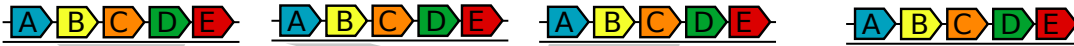

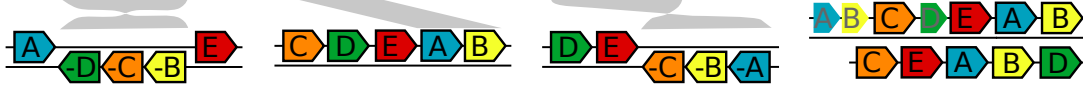

Figure 3: Types of elementary rearrangement events exemplified for an artificial arrangement of five genes; from left to right: inversion, transposition, inverse transposition, tandem duplication random loss; pseudogenisation is represented by missing borders; 